\title{
Do comunismo ao feminismo: a trajetória de Zuleika Alambert*
}

\author{
Rachel Soihet ${ }^{* * *}$
}

\section{Resumo}

$\mathrm{O}$ artigo discute a trajetória de Zuleika Alambert, primeira mulher a participar do Comitê Central do Partido Comunista no Brasil. Analisa o seu processo de tomada de consciência de gênero que a leva a enfatizar a especificidade da questão feminina, discordando das teses tradicionais do referido partido que subordinava tal questão à abolição da propriedade privada e à mudança nas relações de classe. Assim, busca-se mostrar como, paulatinamente, Zuleika aguça suas críticas às posturas daquele partido, ultrapassando suas reticências até sua adesão confessada às propostas feministas.

Palavras-chave: Partido Comunista, Feminismo, Zuleika Alambert, Círculo de Mulheres Brasileiras em Paris, Consciência de Gênero.

\footnotetext{
* Recebido para publicação em 25 de julho de 2011, aceito em 18 de setembro de 2012.

** Professora do Programa de Pós Graduação da Universidade Federal Fluminense.rachelsoihet@globo.com
}

cadernos pagu (40), janeiro-junho de 2013:169-195. 
From Communism to Feminism: Zuleika Alambert's Trajectory

\begin{abstract}
The article discusses Zuleika Alambert's trajectory, the first woman to take part of the Communist Party's Central Committee in Brazil. It analyses how she became aware of her gender conscience which led her to emphasize feminine issue's particularities, disagreeing with traditional theses of the party referred that subordinated that issue to the private property abolition and to class relations' changes. Therefore, it aims to show how Zuleika step by step enhances her criticism of that party's positions, overcoming her reticence until her confessed adhesion to the feminist proposals.
\end{abstract}

Key Words: Communist Party, Feminism, Zuleika Alambert, Circle of Brazilian Women in Paris, Gender Conscience. 
Ia chegar um navio espanhol no cais de Santos. A minha cabeça matutou logo né, não esse navio não pode chegar. Se todos os marinheiros do mundo estavam boicotando os navios de Franco. Eu digo: não, esse navio não pode entrar no cais. Ele não pode descarregar esse navio. Aí eu, a mulher do Graciliano Ramos e a Dona Jovina Pessoa, que é casada com o Samuel Braz de Pessoa do FioCruz fomos pro cais e antigamente não era aquele nojo, o cais tinha paredes onde os ensacadores pegavam a senha para tirar a bagagem que vinha do navio. Eu fui, cheguei lá "ninguém pode (...) tirar, não pode desembarcar esse navio aqui. Não pode descer nenhuma mercadoria dele aqui. De parede em parede, eu falando para os estivadores, né. Menina, chegou o dia que o navio vem vindo lá, vem vindo. Eu fui pro cais $e$ estavam os estivadores todos lá, parados. Eu disse, ninguém vai pegar nada lá. Quero ver como é que ele vai desembarcar isso. Aí eu fiquei líder dos estivadores, inconsciente né, inconsciente. Então eu digo, ninguém vai desembarcar. Eles vão ter que chegar aqui e voltar de onde eles vieram. E eles foram entrando, entrando. Menina, a estiva inteira parou. Todo mundo de braço cruzado e o navio entrando, entrando nenhum tirou nenhum grão de café daquele navio. Aí não puderam descer a carga, fizeram o retorno para voltar, entende? Aí minha filha, os estivadores ficaram enlouquecidos comigo, tudo por acaso... aí depois eu mostro para vocês, Santos resolveu fazer uma homenagem para $\mathrm{mim}^{1}$

O relato acima se constitui em uma marca na trajetória de Zuleika Alambert, que nesse episódio expressa seu inconformismo com a ditadura instaurada por Francisco Franco na Espanha, desde 1939, incentivando o boicote dos trabalhadores do porto de Santos ao desembarque de mercadorias dos navios daquele país. ${ }^{2}$

${ }^{1}$ Entrevista de Zuleika Alambert concedida a Rachel Soihet, em 19 de maio de 2009.

${ }^{2}$ O episódio acima ocorreu em 1946, já durante o governo do Gal. Eurico Gaspar Dutra. 
Nascida em Santos a 23 de dezembro de 1922, Zuleika iniciou sua militância política nos anos 1940, tendo atuação significativa, durante a segunda guerra mundial nas ações $e$ atos realizados na Baixada Santista, participando da Liga de Defesa Nacional, pressionando o governo brasileiro pelo rompimento de relações com os países do Eixo (Alemanha, Itália e Japão), em defesa dos presos políticos, da anistia geral e irrestrita, da redemocratização do país e da convocação da Assembleia Nacional Constituinte. Em 1947, apenas com 23 anos, com amplo apoio dos estivadores, elegeu-se primeira suplente a Deputada Estadual pelo Partido Comunista do Brasil. Logo assumiu o mandato, em substituição ao Deputado Clóvis de Oliveira Neto, que foi afastado pelo partido e a renúncia de seu substituto. ${ }^{3}$ Diante da ilegalidade em que foi colocado o Partido em função da Guerra Fria que se instaurara, os mandatos de seus deputados foram cassados por decisão do Supremo Tribunal Eleitoral, em 1948, e foi expedida ordem de prisão aos deputados comunistas, o que levou a sua passagem para a clandestinidade. Apesar do curto período em que esteve na Assembleia, Zuleika teve atuação destacada na defesa dos interesses dos trabalhadores, em especial, propondo a concessão de um Abono de Natal para os servidores do Estado, visto como um antecedente do $13^{\circ}$ salário que, posteriormente, se instaurou (Acervo Histórico, 2005).

Sua trajetória no PCB pode ser caracterizada como ascendente. Nele foi a primeira mulher no Brasil a se tornar membro do Comitê Central, posição inacessível para a maioria das militantes, embora ela hoje o relativize alegando: "Eu era o álibi. Usada pra dizer 'tem uma mulher lá' e tal" (id.ib.). Isto, porque, segundo a própria Zuleika,

O machismo imperava, e isto aparecia, nitidamente, na divisão dos trabalhos. As mulheres atuavam como

${ }^{3} \mathrm{O}$ afastamento do deputado foi justificado pelo Partido, alegando seu envolvimento com uma menor. 
datilógrafas, taquígrafas nas reuniões do Partido. Serviam cafés, cozinhavam, limpavam os chamados 'aparelhos'. Nas comissões políticas de trabalho eram geralmente eleitas para as comissões gerais, ou seja, aquelas onde cabia de tudo. Para representar o Partido nos Congressos Internacionais jamais eram eleitas e assim por diante (Abreu, 2008:2).

$\mathrm{Na}$ verdade, os comunistas mantiveram com as mulheres uma relação ambígua. Por um lado, acentuavam a necessidade de fazê-las participar de forma mais incisiva das atividades partidárias, a fim de evitar que se aliassem às forças atrasadas $e$ que assumissem concepções burguesas. Por outro lado, o movimento comunista oficial reservava às mulheres um papel subalterno, excluídas das funções politicamente mais relevantes, de maior poder decisório como fica claro na colocação da própria Zuleika. Dessa forma, tornam-se explícitas as relações assimétricas de poder, também nele existentes, confirmando-se a proposição de Scott de que "o gênero não é o único campo, mas ele parece ter constituído um meio persistente e recorrente de tornar eficaz a significação do poder no ocidente, nas tradições judaico-cristã e islâmica" (Scott, 1980:16).

Ainda em meio às lutas das mulheres pelo reconhecimento de direitos, o lema era o de que sua total libertação só seria possível com a instauração do socialismo, diluindo-se toda a sua problemática nas relações de classe. Retirava-se, desse modo, qualquer especificidade no que tange a sua situação. A interpretação de Engels de que a origem da opressão feminina resultara do estabelecimento da propriedade privada e da sociedade de classes mantinha-se como base da subordinação feminina, do que decorria a crença de que somente a derrubada de ambas e o estabelecimento do socialismo selariam a libertação das mulheres. De acordo com essa posição, o texto da III Internacional enfatiza que as mulheres comunistas deveriam rejeitar qualquer tipo de colaboração com as feministas burguesas, pois sua "dupla opressão" - o capitalismo e a dependência 
doméstica - só se resolveria no quadro da "ditadura do proletariado" (Moraes, 2007:349).

Com os movimentos feministas, a partir dos anos 1960 inúmeras foram as situações em que tal pressuposto esteve presente, o que podemos aferir das atitudes tomadas com relação ao Centro da Mulher Brasileira - CMB. Surgida no Rio de Janeiro em 1975, esta entidade enfrentou tanto a vigilância do governo, que via com desconfiança qualquer forma de organização da sociedade, como a oposição dos grupos de esquerda, os quais consideravam que a luta deveria se polarizar contra o governo autoritário e a desigualdade de classes aqui vigente, considerando muitas vezes o feminismo como um fenômeno burguês. Acresce o fato de que particularmente, com relação ao Partido Comunista, observa-se a iniciativa deste em tornar aquelas que dele faziam parte um instrumento para implementação de suas propostas no $\mathrm{CMB}$, conforme depoimento de Santinha ${ }^{4}$, em que reconhece que "foi feita uma reunião do partido em termos de organizar uma base dentro do Centro da Mulher Brasileira" (Soihet, 2007:418).

Igualmente, cabe mencionar a experiência vivida pelo grupo formado em 1972, em Paris, com brasileiras e algumas latinoamericanas, por iniciativa de Danda Prado, o qual assumiu feição similar aos grupos de consciência norte-americanos, ou como aqueles do Mouvement de Libération des Femmes - MLF, na França. Tal grupo tornou-se bastante numeroso, realizando suas reuniões numa sala do subsolo de um bar, próximo ao Quartier Latin (Pedro, 2007:11). Nele, destacava-se a relevância da discussão da sexualidade, considerada uma questão fundamental para a conquista da autonomia para as mulheres através da plena assunção do corpo e da sexualidade (aborto, prazer, contracepção) (Ergas, 1994:601). ${ }^{5}$ Tal autonomia se faria

4 Entrevista da Dra Maria do Espírito Santo Tavares dos Santos (Santinha), concedida em 20 de maio de 2005.

5 Tais ideias eram muito próximas do movimento da contracultura, iniciado nos anos 1960, que se voltava para a crítica dos costumes e da moralidade convencional. A contracultura pode ser entendida como um movimento que teve 
conquistar, através da troca de experiências em pequenos grupos de autoconsciência, espaços nos quais as mulheres compartilhariam experiências e problemas vivenciados nas relações entre os sexos. Esses grupos possibilitariam às mulheres a constatação de problemáticas comuns e a descoberta de que não se tratavam de problemas únicos nem particulares, mas que eram parte da opressão sofrida por todas as mulheres, dando margem ao estabelecimento da irmandade de gênero ou da sororidade (Machado, 1992:26). ${ }^{6}$ Também, partia-se do pressuposto do caráter político das questões ligadas ao cotidiano e ao subjetivo. Nesse sentido, atribuía-se uma dimensão política ao privado, ressaltando o caráter estrutural da dominação e tornando evidentes as modalidades de poder que também se expressam na vida cotidiana, nos diversos aspectos das relações sociais e pessoais, $e$ que, frequentemente, significavam a inferiorização das mulheres (Varikas, 1997:67). Logo se fez sentir a ação da Frente de Brasileiros no Exílio que exigiu canalizar o grupo para tarefas voltadas para o combate à ditadura no Brasil, a partir de sua direção. Ante a recusa de Danda, ameaçaram retirar o apoio às famílias cujas mulheres continuassem participando daquelas reuniões, o que significava a perda de ajuda financeira, emprego, etc. $\mathrm{O}$ argumento era o de que o grupo estava colocando as mulheres contra os homens nos casamentos e nas ligações, contribuindo para desajustar a vida dos companheiros. Como resultado os homens passaram a pressionar suas companheiras para que se afastassem do grupo, do que decorreu a saída de muitas das brasileiras (Goldberg, 1987:71). ${ }^{7}$

origem nos anos 1960, mas pode, igualmente, ser vista como uma posição de crítica radical à cultura convencional.

6 A sororidade correspondia à crença, embora equivocada, na existência de uma essência comum às mulheres o que, naquele momento, contribuiu para o fortalecimento dos feminismos.

7 O grupo Front Brasileiro era formado por homens e mulheres brasileiros, e representantes do PC francês. Todos os grupos tinham representantes no Front, assim como pessoas independentes. Essa era uma forma de se manter a par dos 
Essas posições da esquerda, não apenas no Brasil, como na França ou em outros países ocidentais, levam Christine Delphy a afirmação de que "a esquerda, e mais exatamente a extrema esquerda, foi o interlocutor privilegiado e o "principal inimigo" (Delphy, 1994:189), dos feminismos. Inúmeras mulheres que se engajaram nas lutas em favor das minorias, contra as desigualdades sociais e contra o imperialismo, gradativamente, perceberam a ironia da situação, estavam, igualmente, e em nome dessa luta, numa condição de desigualdade. Manifesta-se, assim, a síndrome do colonizado, paradoxo destacado pelos vietnamitas e argelinos: "é com o país, ou com o sexo colonizador, que aprendemos os valores que ele não nos aplica, e que retornamos então contra ele". Compreende-se, daí a apropriação da palavra "liberação", associada às lutas contra o colonialismo, por correntes feministas, tornando-se metáfora instrumental para a confecção de um sentimento de solidariedade de gênero (id.ib.).

É nesse contexto que Zuleika Alambert entrou em contato mais de perto com os feminismos. Em 1970, asilou-se no Chile, durante o governo de Salvador Allende, diante do acirramento das perseguições movidas pela ditadura contra as esquerdas. Nesse momento, não teria sentido a sensação de exílio, tal o seu entusiasmo com a experiência que estava ocorrendo naquele país. Acentua que naquela ocasião preocupou-se em trabalhar politicamente as mulheres brasileiras que ali se encontraram. De acordo com algumas fontes, essa seria uma incumbência que lhe foi atribuída pelo Partido Comunista a fim de organizar e conscientizar as mulheres, do que resultou o Comitê de Mulheres Brasileiras no Exílio (Pedro e Wolff, 2007:64). Mas, segundo suas palavras, ela teria assumido esse papel, também, diante das posições conservadoras assumidas pelas mulheres, frente aos

acontecimentos no Brasil, além de obter a entrada de crianças na escola, encontrar apartamento e trabalho, enfim tudo era o Front que conseguia. Quem participasse do Nosotras e do Grupo Latino-americano de Mulheres estaria fora da rede de ajuda do Front. 
movimentos revolucionários, como ocorrera no Brasil com aquelas que apoiaram o golpe militar de 1964 e com aquelas que se manifestavam contra o governo da Unidade Popular no Chile, exemplificando com a célebre marcha das panelas vazias. Mas, também, sentia-se motivada, diz ela:

porque eu via as mulheres brasileiras muito dependentes dos seus maridos. A maioria dos exilados eram homens, que levavam as suas famílias. Então as mulheres eram as mulheres dos exilados. O que não quer dizer que não houvesse algumas dezenas que tivessem participado em ações políticas no Brasil, e por causa disso tivessem também de buscar o exílio. Mas a grande maioria estava lá em função dos maridos e eram as grandes marginalizadas. Marginalizadas da sociedade chilena, porque não eram chilenas, não falavam nem a língua. Marginalizadas como mulheres dentro das suas próprias famílias, porque os homens eram políticos, continuavam as suas ações, e elas ficavam em casa (Costa et alii, 1980:60).

$\mathrm{E}$, a seguir, enumera uma série de realizações levadas a efeito com vista à participação dessas mulheres, dentre elas a ideia de criação do citado Comitê, em que pese a ressalva de que este seria um movimento "feminino e não feminista". Um Seminário Latino-Americano de Mulheres para discutir a problemática da mulher no continente foi também uma de suas iniciativas. $\mathrm{Na}$ verdade, tal Comitê enfatizava uma proposta coerente com as concepções dos comunistas sobre as formas em que deveria ocorrer a participação das mulheres, a partir das questões gerais, com menção a algumas situações delas como mães. Nenhuma possibilidade se abria ao enfoque de assuntos mais específicos de acordo com o que as feministas estavam reivindicando, em termos do corpo, da sexualidade, da hierarquia entre mulheres e homens. Assim, propunha-se a lutar pela emancipação da mulher, o que deveria se concretizar através da emancipação política, econômica e social do país, denunciando-se a política da ditadura em todos 
os níveis - prisões, torturas e assassinatos de revolucionários - o que no momento seria o ponto alto da campanha. Ainda foram feitas referências ao propósito de estudar problemas relacionados com a mulher, quanto à luta por direitos formulados de maneira vaga, direitos de seus filhos e pela sua emancipação como mães. Finalizava, ressaltando que sua verdadeira emancipação somente seria alcançada, a partir da libertação de todo o seu povo. Mas, de acordo com a entrevista de Zuleika Alambert a Albertina de Oliveira Costa (id.ib.:60-61), nele se teria dado "o primeiro despertar para o problema específico da mulher", atentando-se, ainda de forma limitada para problemas como planejamento familiar, divórcio, aborto e falta de trabalho.

Em meio à ida para a Europa e a emergência das questões especificamente feministas, segundo sua percepção nos dias de hoje, teria ela se voltado para a sua própria condição, levando a efeito uma reavaliação de sua trajetória.

$\mathrm{Na}$ França é que eu entrei em contato com grupos feministas e aí comecei a frequentar eles lá e aí aprendi muita coisa do feminismo naquela época, hoje eu acho que eu sou mais feminista que qualquer feminista, porque eu digo, eu sou eco-feminista (id.ib.:60-61).

Cabe ressaltar que paralelamente ocorria uma mudança na posição do Partido Comunista com relação às mulheres. Nesse sentido, é bastante representativo um documento de janeiro de 1975, "Trabalho do Partido entre as mulheres". De acordo com esse documento, o Partido "em todo o curso de sua existência, sempre teve preocupação, embora formal, com a mulher". É ressaltada a pequena presença de mulheres militantes e a quase inexistência de "quadros femininos" nas direções, a falta de uma política clara em relação às mulheres, a precária participação nos eventos internacionais e o desaparecimento dos órgãos femininos. E conclui que o partido "nunca encarou com profundidade a questão da mulher, tanto teoricamente como politicamente". Era necessária 
uma batalha "interna" e "externa" para superar esse estado de coisas. O problema não podia mais ser adiado, dizia o documento. Por isso, propõe-se a criação de seções femininas, promoção de quadros femininos em pé de igualdade com os quadros masculinos, estudo da condição da mulher e um combate às tendências patriarcais e machistas no seio do Partido (Abreu, 2008:5).

Em meio a esse debate, tomava vulto o Círculo de Mulheres Brasileiras em Paris, em abril de 1976, constituído por vinte mulheres, embora tivessem publicado um boletim, desde 1975, que durou até 1979. A sede das reuniões era a Maison Du Brésil e segundo Anette Goldberg, uma de suas integrantes, tiveram forte influência do feminismo francês. O Círculo chegou a contar com cem mulheres, a maioria na faixa dos 30 anos, que iam se repartindo em subgrupos segundo suas amizades e/ou preferências por temas de discussão e/ou práticas desenvolvidas. Uma coordenação, composta por uma representante de cada subgrupo designada em sistema de rodízio, deveria agilizar a circulação de informações no interior do Círculo, e uma Assembleia Geral se reunia mensalmente para debater temas considerados mais importantes e tomar decisões (Goldberg, 1987:150).

De composição muito heterogênea, com diferentes motivações e vivências, distintas procedências em termos sociais e/ou regionais, marcadas ou não por uma experiência militante, as feministas do Círculo disseminavam duas orientações nem sempre de maneira assumida e explícita. A primeira orientação provinha da tendência constituída por mulheres inspiradas pela vertente "luta de classes" do movimento francês que defendiam a dupla militância (atuação simultânea no Círculo e nos grupos da esquerda brasileira), como da nova-esquerda dos Estados Unidos. Preocupavam-se com a conscientização das demais mulheres com relação às lutas "mais gerais" da sociedade brasileira e às lutas "específicas" das trabalhadoras, além de desenvolver práticas voltadas para essa tarefa. Embora afirmassem que uma igualdade plena entre mulheres $e$ homens só se efetivasse numa sociedade sem classes, a luta deveria começar no âmbito do capitalismo. 
Assim, elas se dedicavam ao estudo e à reflexão teórica, tendo produzido textos para discussão sobre o trabalho feminino e sobre as tendências do feminismo internacional, análises críticas dos editoriais e do conteúdo dos jornais brasileiros Brasil Mulher e Nós Mulheres, além de documentos lidos e divulgados em atos públicos e reuniões de diversos tipos.

A outra orientação presente nos subgrupos era quantitativamente minoritária, representada majoritariamente por mulheres mais jovens do que a média, motivadas pelo aspecto contracultural, libertário e utópico dos novos movimentos de liberação das mulheres. Delas provinha o estímulo das "novas práticas", graças a elas se fez reflexão sobre o "vivido" das próprias participantes, discutiu-se problemas da individuação feminina, relações entre as mulheres e entre os sexos, falou-se do amor e de emoções, deu-se grande ênfase às questões da sexualidade $e$ do corpo $e$ incluíram-se aspectos lúdicos $e$ prazerosos nas práticas desenvolvidas. Para essa tendência não seriam importantes os resultados, mas "o fenômeno de ruptura na subjetividade coletiva", que se expressaria, entre outros, através dos escritos de Félix Guattari, Michel Foucault, Claude Lefort (id.ib.:151).

A influência já estabelecida do Círculo entre a comunidade exilada teria impedido a formação de órgãos femininos do próprio Partido. Nesse sentido, o Comitê Central do PCB convocou reuniões, a fim de discutir a questão feminina, das quais a discussão mais consistente ocorreu na França, entre 1976 e 1979, sendo produzidos diversos documentos, dentre eles um parecer considerando fundamentais os problemas abordados $e$ as discussões realizadas no âmbito do Círculo. Embora fizessem uma referência irônica às "deformações ideológicas 'sexistas' que se manifestam em numerosos enfoques", reafirmavam a importância dos temas presentes nos debates, refletindo problemas reais que tendiam a crescer na consciência de um número cada vez maior de mulheres. Afirmavam ser imprescindível uma maior atenção em face de temas tais como o da sexualidade, o das relações entre homem e mulher, o da família, o da transmissão de papéis 
masculinos e femininos através da educação, o do controle de natalidade, etc. (Abreu, 2008:6).

Observa-se, dessa forma, uma mudança na posição do Partido com relação às questões das mulheres e o termo feminismo foi apresentado de forma positiva nos debates aí ocorridos. Concluiu-se acerca da necessidade de um movimento específico contra estas formas de exploração, devendo se acrescentar à luta pela emancipação do proletariado a luta pela emancipação das mulheres. E, numa clara referência aos grupos de reflexão acentuava-se que tal luta deveria partir dos problemas vivenciados pelas mulheres. Críticas foram feitas a outros grupos que mantinham uma política para as mulheres similar àquela anteriormente levada a efeito pelo Partido. Também foi manifestado o empenho do partido em levar a FDIM - Federação Democrática Internacional de Mulheres a implementar uma política, coerente com os novos pressupostos assumidos pelo Partido no que tangia à problemática feminina (DPCB-fevereiro de 1978). ${ }^{8}$

Como resultado desse contato e de sua participação na elaboração dessas medidas, mas também de uma problemática existencial - o rompimento de sua relação afetiva com Armênio Guedes, igualmente membro do Comitê Central do Partido Comunista e seu companheiro durante 27 anos - tais questões muito mobilizaram Zuleika e, segundo suas palavras: "Foi aí que comecei a analisar as coisas. A tentar entender porque uma mulher liberada que tinha feito tudo que queria, ameaçava desmontar-se pela questão afetiva" (Jornal República, 05.11.1979). E ela que se julgava uma mulher "plenamente libertada" tomou consciência de uma série de dependências, o que aguçou sua sensibilidade para entender não apenas suas dificuldades do passado, mas também das coisas que teria de superar para poder dar uma real contribuição à causa para a qual lutava. Evidenciase, nesse particular, uma estreita relação entre os afetos e o

8 Cf. Abreu, 2008. 
político, entre o sujeito individual em sua afetividade e as práticas sociais e políticas (Ansart, 2004:15).

Igualmente, para ela, o exílio foi um elemento significativo para que essas questões aflorassem. $\mathrm{O}$ que se depreende de suas declarações de que

Se não senti o exílio no Chile, com a vinda para a Europa as coisas se tornaram muito diferentes. (...) E, pela primeira vez me senti exilada. Quer dizer: você está num lugar que não é o seu, que não te pertence. Não me sinto integrada por mais que me interesse pela vida, pelos hábitos, pela cultura do país em que vivo (Costa, 1980:63).

$\mathrm{E}$, mais adiante, assume ter adquirido um ganho com relação a questões para as quais até então não atentara:

As coisas que pude aprender na Europa. Os instrumentos que adquiri de análise e compreensão da mulher na sociedade me levariam a ter um senso crítico muito agudo para a sua aplicação à realidade brasileira. No Brasil temos de começar muito de baixo, de coisas muito pequenas. Tenho a impressão de que só muito recentemente começa a surgir lá uma noção muito clara de que a mulher, além de ser explorada como todo trabalhador, tem uma exploração adicional, específica (id.ib.:64).

$\mathrm{E}$, em seguida, enumera uma série de experiências que denotam situações de dependência feminina, acentuando a sua problemática familiar, para a qual, entre outros, cita o autoritarismo de seu pai e o sofrimento de sua mãe; o sentimento de propriedade com relação ao outro; a busca de identificação pelas mulheres aos gostos masculinos, quanto a filmes, músicas etc. e o relacionamento afetivo como razão fundamental da existência. Ainda, refere-se à instrumentalização dos movimentos de mulheres pelos partidos políticos, afirmando que estes lançavam mão da mobilização das mulheres, mas passada a 
necessidade, elas eram postas de lado. Refere-se aos novos tempos, nos quais as mulheres gritam por autonomia, não mais se deixando instrumentalizar, o que não quer dizer que tais movimentos autônomos sejam apolíticos.

É evidente que são políticos, porque dentro dos
movimentos há mulheres políticas. Mas só que elas estão lá
para debater democraticamente os problemas das
mulheres, não para transformar essas organizações em
pequenos biombos dos partidos políticos, que não são
monopólios dos partidos: recusam-se a serem
instrumentalizados (id.ib.:67).

De qualquer forma, esse processo de tomada de consciência de gênero (Perrot, 2005:281), em termos de consciência de sua opressão enquanto mulher, parafraseando E. P. Thompson (1984:37), para o qual é no processo de luta que os explorados descobrem-se como classe ocorreu de forma gradativa. Assim é que, perguntada se era feminista, em entrevista ao voltar para o Brasil, respondeu negativamente, acrescentando: "Sou uma marxista que se dedica ao problema da mulher" (Jornal República, 05.11.1979). Mas, referiu-se de forma positiva às feministas, por terem levantado a questão cultural, ou seja, "a necessidade de se mudar a cabeça dos homens e das mulheres"; questão que teria sido, segundo ela, subestimada pelos comunistas que se mantiveram economicistas, acreditando que a mudança das relações de classe significaria automaticamente a resolução dos problemas das mulheres. Reiterou, porém, que as feministas "omitiram a premissa básica para a solução da opressão feminina, que é realmente o fim da dominação de classes" (id.ib.).

De volta ao Brasil, em fins de 1979, Zuleika Alambert desenvolveu esforços para implementar tais ideias. Logo fez uma série de declarações em que tais pressupostos ficam explícitos. Lembre-se que esse momento marcou a volta das demais exiladas com viva influência dos feminismos, especialmente europeus, o 
que, aliado à experiência daquelas que permaneceram no país nos anos 1970 e que construíram os feminismos locais, contribuiu para dar a esses movimentos no país uma nova configuração. Igualmente, a anistia representou uma época de maior liberalização, menos repressão e mais possibilidades de manifestação, inclusive porque o $\mathrm{AI}-5$ não mais estava em vigor (Sarti, 2004:40). Assim é que em matéria realizada quando de seu desembarque, foi colocado o seu empenho em participar dos movimentos de emancipação da mulher "que sempre foram a razão da minha vida" completava ela. E, mais adiante, informava que no ano anterior conseguira fazer aprovar no Comitê Central do PCB uma resolução sobre a "Condição da Mulher na Sociedade Brasileira" que admitia entre outras coisas, que "seria um erro pensar que a conquista de importantes reivindicações das mulheres só se dará com a extinção do capitalismo". ${ }^{9} \mathrm{Na}$ mesma ocasião, em outro jornal já o título da matéria - "Comunista vai lutar contra o machismo até mesmo no PCB" - deixava clara sua aproximação com tais questões. $\mathrm{E}$, mais adiante, completava que não haveria democracia no Brasil "enquanto as mulheres forem marginalizadas", acrescentando seu empenho em lutar pela igualdade dos direitos da mulher até mesmo no PCB, pois seus integrantes "como homens da sociedade brasileira trazem toda carga de preconceitos e coisas erradas no tratamento com as mulheres". ${ }^{10}$ Essa é uma tecla, a partir daí, acionada a todo instante, repetindo a sua preocupação de trabalhar junto às mulheres (Jornal República, 05.11.1979).

$\mathrm{E}$, com o passar do tempo, suas críticas se tornam mais profundas, além de referir-se explicitamente ao feminismo como alvo de sua atenção, dando mostras da elevação de sua consciência de gênero. Fato que pode ser constatado ao

${ }^{9}$ Chega hoje Zuleika da cúpula do PCB. S/D. Arquivo pessoal de Zuleika Alambert.

${ }^{10}$ Comunista vai lutar contra o machismo até mesmo no PCB. S/D. Arquivo pessoal de Zuleika Alambert. 
manifestar sua surpresa "ao ver no Brasil, como as brasileiras têm abordado com naturalidade e seriedade questões tidas há pouco tempo atrás como coisas "proibidas", tais como o aborto, a frigidez sexual, etc." (Diário de Pernambuco, 21.06.1980). Posteriormente, em longo artigo, fazendo referência ao III Congresso da Mulher Paulista que teria se realizado três meses antes, criticou os partidos políticos que, em sua maioria, continuariam manipulando os movimentos sociais das mulheres $e$ as entidades femininas como se esses fizessem parte deles, ou se constituíssem em simples prolongamento da organização partidária. Nesse sentido, acentua que somente através de um movimento autônomo, as mulheres seriam capazes de perceber a singularidade da questão feminina, ficando aptas a fazer propostas que transformassem a luta feminista num importante segmento do movimento democrático (Voz da Unidade, 29.05 a 04.06.1981).

Os congressos realizados, disse ela, tanto aquele do Pacaembu, quanto o do Teatro da Universidade Católica de São Paulo - TUCA, ocuparam quase todo o seu tempo discutindo os problemas gerais do país e do mundo em detrimento das reivindicações femininas. Assim as congressistas paulistas perderam uma oportunidade de discutir temas importantes:

como o da discriminação da mulher no local de trabalho (...) e o parto, o cuidado dos filhos, o papel secundário na administração do núcleo familiar, as condições deprimentes do trabalho doméstico e a dependência econômica, jurídica, cultural, sexual e afetiva da esposa em relação ao marido. Além destes, toda uma série de problemas sóciopolíticos vinculados à mulher, como de sua saúde, o da prostituição, o da delinquência e exploração da menor, o da mãe solteira, o do analfabetismo, o da imagem estereotipada da mulher pelos meios de comunicação de massa etc. não foram sequer tocados (id.ib.).

Também nenhuma manifestação ocorreu, a fim de denunciar e condenar a ausência quase total de mulheres nos 
postos políticos e administrativos do país e na direção das organizações democráticas, em qualquer dos seus escalões $e$ níveis. Essa imensa gama de questões que compõem o quadro de alienação e de marginalidade da mulher na sociedade deixou de ser discutida, disse ela ironicamente, por serem consideradas de menor importância, podendo ficar para "um depois". Afirmação essa que coincidia com aquela da intelectual francesa Christine Delphy (1994:189), a qual acentuara ser característica recorrente nos domínios esquerdistas de transferir indefinidamente a discussão sobre a situação das mulheres. Em consequência, tais problemas, continuava Zuleika, poderiam ser resolvidos após a solução de todos os outros problemas do país. E, até lá, as mulheres que continuassem a desempenhar seus papéis de esposas, de donas de casa e de mães de família com abnegação e paciência. Que continuassem como um objeto incapaz de pensar e agir por conta própria... (id.ib.).

Zuleika aproveitou para criticar os partidos que não reconheciam a autonomia do movimento de massas e em especial do movimento de mulheres; deixou clara a sua posição com relação ao comunismo naquele momento, o que já mencionara ao voltar da França, quando se afirmara admiradora dos chamados "euros", em particular das experiências dos PCs da Itália, Espanha e França (Jornal República. 05.11.1979). Dessa forma, criticava a linha assumida de exclusivismo partidário, "ignorando o pluralismo que a vida está impondo e a luta democrática pede que se leve em consideração" (Voz da Unidade, 29.05 a 04.06.1981).

Com relação aos movimentos feministas, os partidos teriam uma função positiva e importante se buscassem compreender a condição feminina e acionar os instrumentos capazes de introduzir mudanças nessa condição. Mas para isto acontecer, os partidos teriam que tomar consciência do valor político da mulher na sociedade, da singularidade de sua condição e deixarem de considerá-la um objeto acionável apenas no momento em que dela necessitam, seja como força eleitoral, seja como massa de pressão. E, de outro, e isso é o mais importante - tal mudança de 
postura somente ocorreria se as mulheres adquirissem consciência de si próprias, de sua condição, da situação marginal e de dependência em que se encontravam. E também se deixassem de aceitar a manipulação dos partidos com a mesma docilidade com que aceitavam a do patrão, do pai e do marido (id.ib.).

Cinco anos após sua chegada ao Brasil, ou seja, em 1984, Zuleika recebeu a medalha Anchieta e o Diploma de Gratidão da Cidade de São Paulo, homenageada pela Câmara Municipal da referida cidade. $\mathrm{Na}$ ocasião, pronunciou um discurso em que proclamava a importância da democracia para a América Latina, naquele momento, no qual se constatava a influência das mudanças no Partido Comunista italiano. Também, remontou a sua chegada ao Brasil, quando se reunira com 200 mulheres comunistas. $e$ todas lhe afirmaram que para desenvolver seu trabalho junto às massas femininas, a primeira coisa que tinham a fazer era se desligarem da máquina partidária. Tal contradição ela vinha sentindo há muito tempo, dando-se conta de que para o desenvolvimento de seu trabalho deveria se desligar daquela forma orgânica.

Assim, se referiu à Resolução Política de maio de 1979, elaborada pelo Coletivo de Mulheres Brasileiras no Exilio e atualizada posteriormente em abril de 1982 que trata da questão das mulheres para os comunistas. Acentuou seu caráter inovador porque

pela primeira vez a mulher é considerada não como simples instrumento de mobilização para as atividades politicas em geral e sim como protagonista da luta pela sua emancipação $e$ libertação e na conquista de seu espaço na vida nacional nos planos econômico, social, político e cultural. ${ }^{11}$

Em que pese ter sido aprovada pela direção, o encaminhamento político da proposta teria sofrido muita resistência, sendo necessário que algumas mulheres, de forma

${ }^{11}$ Zuleika Alambert não está cansada da guerra. S/D. Arquivo pessoal Zuleika Alambert. 
independente da citada direção, tomassem a iniciativa de divulgála junto à sociedade. Teria, então, Zuleika percebido que o mesmo problema estava ocorrendo em outras áreas, como por exemplo, sindical, estudantil, cultural, etc. Do que resultara que as pessoas que vinham lutando pela renovação e adaptação do partido às novas exigências da sociedade estivessem alijadas da estrutura partidária, dando mostras das dissensões que no momento assolavam o Partido e que resultariam, inclusive, em seu afastamento dele.

Como sinal dos novos tempos de reconhecimento da legitimidade do feminismo por alguma das vertentes do comunismo, assistiu-se em 1980 à publicação de um número especial todo dedicado à mulher da Revista Encontros com a Civilização Brasileira, cujo diretor era Ênio Silveira, membro do Partido Comunista. ${ }^{12}$ Nele, Zuleika Alambert (1980:105) publicou um artigo, no qual discorreu acerca das contribuições teóricas dos marxistas sobre a mulher, por meio do qual se pode captar a sua posição acerca da questão naquele momento que coincidia em muitos pontos com aquelas de lideranças passadas como Alexandra Kollontai e Clara Zetkin. Após uma retrospectiva acerca das transformações e dos recuos ocorridos a partir da Revolução Francesa, aludiu ao pensamento socialista pré-marxista, o qual afirmava que os progressos sociais se medem em razão do progresso da mulher em relação à liberdade, mas que não teria tido, segundo ela, a profundidade suficiente para despertar um movimento à altura de lutar pela emancipação da mulher - ideia discutível se se lembrar das colocações de Charles Fourier que teriam influenciado o jovem Marx, acerca de que "o grau de emancipação das mulheres é a medida natural da emancipação geral", pois "a mudança de uma época histórica pode ser sempre determinada pelo progresso das mulheres no sentido da liberdade" (Nye, 1995:71). Fourier também influenciou a atuação de várias líderes feministas na época, entre outras, Flora Tristan,

${ }^{12}$ Trata-se do volume 26 intitulado Mulher Hoje. 
Jeanne Déroin e Claire Demar (Riot-Sarcey, 2002:27). O movimento feminista, ao contrário, continuou Zuleika, conseguira travar lutas de grande amplitude, principalmente na Inglaterra, onde a luta das suffragettes pelo direito de voto se chocara com a violência governamental.

No mesmo artigo, Zuleika reconheceu, em razão das novas diretrizes, que o movimento feminista pelos direitos da mulher e a ação socialista no mesmo sentido (porém voltada exclusivamente para a mulher trabalhadora) se desenvolveram separadamente $e$ muitas vezes em oposição recíproca. $\mathrm{E}$, em razão desse erro evidente teria se originado a subestimação posterior, por parte dos partidos comunistas, da especificidade da questão da mulher (Alambert, 1980:115). Rebateu, em seguida, as críticas feitas pelo movimento feminista moderno às ideias de Lenin sobre a relação homem-mulher, sobre a questão da sexualidade, o casamento, o amor livre. Ideias que, segundo ela, foram deturpadas e utilizadas como argumento para o retorno ao moralismo sexual que caracterizou a sociedade soviética por tanto tempo; um moralismo sancionado juridicamente em 1936, e que influiu negativamente sobre a vida posterior dos países socialistas e partidos comunistas do mundo inteiro.

$\mathrm{Na}$ verdade, Zuleika resistiu a enxergar as reticências de Lenin que, ante às preocupações por ele consideradas excessivas com os fatos da intimidade, afirmava ser impossível legislar profundamente, com relação às vidas privadas. E julgava repugnante e impróprio que os socialistas estivessem sempre "remexendo coisas ruins" demonstrando seu conservadorismo em questões sexuais, fato que se observa nos seus diálogos com Clara Zetkin, nos quais discorda das atenções dela, para ele desmedidas, com as questões de sexo e casamento. E que eram, prosseguia Lenin, "toda essa conversa de Freud?" (Nye, 1995:65). Sexo não era assunto para as mulheres tratarem; em vez disso deviam discutir sobre salários, desemprego, impostos. Quando essas questões estivessem resolvidas, o restante entraria nos eixos. Afinal, a discussão da sexualidade era não só desnecessária como 
perigosa. Levaria a excessos, principalmente entre os jovens que deveriam ser incentivados a aplicar suas energias no exercício, estudo e política, e não em distração romântica (id.ib.:66).

Referia-se Zuleika ao Congresso da III Internacional Comunista realizado em Moscou, de 22 de junho a 12 de julho de 1921, cuja $20^{\mathrm{a}}$ Sessão foi dedicada à discussão das Teses sobre Métodos e Formas de Trabalho do Partido Comunista entre as Mulheres, nos Países Soviéticos, Atrasados e Capitalistas. No que tangia aos países capitalistas considerou que a orientação não foi das mais corretas, proibindo qualquer colaboração com 0 movimento feminista burguês.

O marasmo existente no movimento marxista, no que tangia à elaboração teórica sobre a mulher teria se rompido com o Partido Comunista Italiano sob a liderança de Palmiro Togliatti, no período de 1945 a 1970, cuja atuação foi ressaltada por Zuleika. Pela primeira vez, um dirigente político disse à mulher que ela não deveria continuar a se sacrificar, a sofrer em silêncio pelo bem da pátria, como, aliás, sempre fez, mas que para o bem da pátria ela deveria falar, agir, lutar por seus direitos. Com a mesma força, Togliatti indicou os instrumentos a serem usados nessa luta. Segundo ele, a unidade das mulheres seria a primeira condição, ou seja, a unidade entre as mulheres de todas as classes e estratos sociais. Ainda, referia-se Zuleika ao livro La Questionne Femminile, de Carla Ravaioli que contém nove entrevistas com importantes personalidades do $\mathrm{PCI}$, no qual estão contidas contribuições relativas a importantes temas, tais como: público $e$ privado, a reapropriação do corpo, aborto, relação homemmulher etc. Nessas entrevistas havia todo um esforço dos marxistas italianos no sentido de incorporar a sua política para as mulheres toda a rica contribuição do movimento feminista internacional e italiano da década de 1960 (Alambert, 1980:124). Concluiu que não bastava afirmar que a superação da sociedade classista era fator básico para a emancipação da mulher, ou então que a massiva entrada das mulheres na produção iria libertá-las. As mulheres esperavam e lutavam por algo mais do que isso. 
Defendendo o primado do material sobre o cultural, não deveriam deixar este para as calendas gregas, para depois da revolução socialista. Tornara-se necessário e urgente restabelecer o vínculo dialético entre a base material, econômica e a superestrutura, a cultura que, embora fluindo da primeira, depois de certo tempo adquire uma dinâmica própria e continua a existir, mesmo que a base econômica que lhe deu origem tenha sido liquidada; isso para não falar da influência permanente que exerce sobre ela.

A recepção a essas ideias não parece ter sido das mais entusiastas, ao menos na URSS, conforme matéria em que um personagem daquele país conclamava os homens a assumirem a liderança do lar, cabendo às mulheres se encarregarem da louça suja. Entrevistada, Zuleika afirma

Eu vejo mal essas relações entre a esquerda e o feminismo. A esquerda no Brasil nunca se preocupou com o problema da mulher. Alegou-se sempre que era preciso cuidar primeiro do geral para depois tratar do específico. Acontece é que não existe geral sem específico. As esquerdas não só no Brasil, como no mundo inteiro (Berlinguer na Itália era uma exceção) não estão vendo que um dos acontecimentos mais importantes deste século é a emergência das mulheres em todo o mundo. ${ }^{13}$

Discorre a seguir sobre sua experiência na União Soviética, onde estivera por largo tempo, durante seus anos de exílio (19701979). Afirma que os soviéticos não enfrentavam as questões relativas à especificidade feminina, alegando "que a mulher participou da revolução ao lado dos homens, trabalha e estuda como eles, e que, portanto não há mais nada a reivindicar". Fato com o qual não concordava, já que embora a mulher fosse valorizada legalmente, havia toda uma questão cultural que impedia de fato uma situação igualitária entre mulheres e homens. Assim, embora $98 \%$ das mulheres estivessem trabalhando, ficavam

${ }^{13}$ Às camaradas, o fogão. Arquivo Pessoal Zuleika Alambert. 18.09.1984. 
relegadas às profissões mais mal remuneradas e de menor prestígio. Embora houvesse inúmeras mulheres médicas pediatras, ginecologistas e clínicas gerais, os grandes especialistas eram homens. Sem esquecer o problema da dupla jornada, ou seja, o cuidado da casa e dos filhos que continuava sob a responsabilidade exclusiva da mulher. Cita o exemplo de um casal de físicos em que o marido estava se preparando para ingressar na Academia de Ciências, enquanto a esposa não podia fazê-lo, alegando ter que cuidar do filho. ${ }^{14}$

Essas ideias apesar de formalmente aceitas pela direção do Partido no Brasil, segundo palavras da própria Zuleika, de fato, não foram devidamente incorporadas por ele, o que a leva a afirmar que "eu briguei com o Partido porque eles não queriam saber das mulheres". Nesse sentido, constata-se que o contato com os feminismos, em uma situação de exílio, ao que se acrescia uma experiência das mais traumáticas, qual seja, o rompimento da relação após 27 anos de vida em comum com o seu companheiro, possibilitaram a Zuleika Alambert a emergência de uma consciência de gênero. Nesse sentido, questões antes colocadas em segundo plano, vistas como próprias à esfera privada, tais como as relativas ao corpo, ao desejo, à sexualidade, à violência, foram legitimadas e trazidas à esfera pública, reconhecendo sua dimensão política. Parte para a afirmação do universo cultural feminino e sem abandonar as preocupações com as lutas gerais, temas tabus são trazidos à tona, forçando o alargamento e democratização daquele espaço (Rago, 2003:5). Não mais aceitou transferir a discussão sobre a situação das mulheres para "depois da libertação deste ou daquele povo, depois do fim do racismo, depois da liberação dos proletários, depois da Revolução - enfim, depois de tudo (Delphy, 1994:193).

${ }^{14}$ Idem, Ibidem. 


\section{Referências bibliográficas}

ABREU, Maira Luisa Gonçalves de. O PCB e a Questão Feminina (19701979). Florianópolis. Fazendo Gênero 8 - Corpo, Violência e Poder, 25 a 28 de agosto de 2008. Disponível em: $<$ http://www.fazendogenero8.ufsc.br/sts/ST45/Maira_Luisa_Goncalve s_de_Abreu_45.pdf $>$. Acesso em: 29.08.2009.

ACervo HistóRICO. Peço a Palavra: Deputada Zuleika Alambert. Acervo Histórico 3, São Paulo, Assembleia Legislativa do Estado de São Paulo, $1^{\circ}$ semestre 2005, pp.32-45.

AlAMBERT, Zuleika. Os Marxistas e a Elaboração Teórica sobre a Mulher. Encontros com a Civilização Brasileira, vol. 26. A Mulher Hoje. Rio de Janeiro, Civilização Brasileira, 1980, pp.105-125.

ANSART, Pierre. História e memória dos ressentimentos In: BRESCIANI, Stella e NAXARA, Márcia. (orgs.) Memória e (Res) sentimento: indagações sobre uma questão sensível. São Paulo, Editora da Unicamp, 2004, pp.15-36.

Costa, Albertina de Oliveira et alii. (orgs.) Memórias das Mulheres do Exílio, vol. 2. Rio de Janeiro, Paz e Terra, 1980.

DELPHY, Christine. Feminismo e Recomposição da Esquerda. Revista Estudos Feministas, vol. 2, n 3 . Rio de Janeiro, CIEC-UFRJ, 1994, pp.187-199.

ERGAS, Yasmine. O sujeito mulher. O feminismo dos anos 1960-1980. In: DuBY, Georges e PERROT, Michèlle. História das Mulheres no Ocidente. Vol. 5. Porto, Afrontamento, 1994, pp.583-611.

GoldBerG, Anette. Feminismo e Autoritarismo. A Metamorfose de uma Utopia de Liberação em Ideologia Liberalizante. Dissertação de Mestrado, UFRJ, Rio de Janeiro, 1987.

MACHADO, Lia Zanotta. Feminismo, Academia e Interdisciplinaridade. In: COSTA, Albertina de Oliveira e BRUSCHINI, Cristina. (orgs) Uma Questão de Gênero, Ed. Rosa dos Tempos, 1992, pp.24-38.

MORAES, Maria Lygia Quartim de. O Encontro Marxismo-Feminismo no Brasil. In: RIDENTI, Marcelo e REIS, Daniel Aarão. (org.) História do 
Marxismo no Brasil, Campinas - SP, Editora da Unicamp, 2007, pp.341-373.

NYE, Andrea. Teoria Feminista e as Filosofias do Homem. Rio de Janeiro, Editora Rosa dos Tempos, 1995.

PEDRO, Joana Maria e WolfF, Cristina Scheibe. Nosotras e o Círculo de Mulheres Brasileiras: feminismo tropical em Paris. Art Cultura. Revista de História, Cultura e Artes, vol. 9, $\mathrm{n}^{\circ}$ 14, Uberlândia, EDUFU, janjun. 2007, pp.55-69.

PEDRO, Joana Maria. Nosotras, Nós Mulheres, Nos/Otras, Noidonne Rede de Divulgação Feminista dos anos 70 e 80. In: WolfF, Cristina Scheibe, FAVERI, Marlene de, RAMOS, Tânia Regina de Oliveira. (orgs.) Leituras em Rede. Gênero e Preconceitos. Florianópolis, Mulheres, 2007, pp.307-327.

Pereira, Carlos Alberto M. O que é Contracultura. São Paulo, Editora Brasiliense, 1983.

PERROT, Michelle. Sair. In: As Mulheres e os Silêncios da História. BauruSP, EDUSC, 2005, pp.279-316.

PINTO, Céli Regina Jardim. Uma história do feminismo no Brasil. São Paulo, Editora Fundação Perseu Abramo, 2003.

RAGO, Margareth. Os feminismos no Brasil: dos anos de chumbo à era global. Labrys, estudos feministas, $\mathrm{n}^{\circ}$ 3, janeiro/julho de 2003. Disponível em:<www.labrys.net.br> . Acesso em: 22/07/2011.

RIOT-SARCEY, Michèle. Histoire du féminisme. Paris, Éditions La Découverte, 2002.

SARTI, Cynthia Andersen. O feminismo brasileiro desde os anos 1970: revisitando uma trajetória. Revista Estudos Feministas, Florianópolis, 12 (2), CFH/CCE/UFSC, 2004, pp.35-50.

SARTI, Cynthia Andersen. Feminismo e contexto: lições do caso brasileiro. Cadernos Pagu (16), Campinas-SP, Núcleo de Estudos de Gênero- Pagu/Unicamp, 2001, pp.31-48.

ScOTT, Joan. Gênero: uma categoria útil para análise histórica. Recife, 1989, mimeo. [Tradução: Christine Rufino Dabat \& Maria Betânia Ávila] 
SOIHET, Rachel. Feminismos e Cultura Política: uma questão no Rio de Janeiro dos anos 1970-1980. In: ABREU, Martha, SOIHET, Rachel, GonTIJO, Rebeca. (orgs.) Cultura Política e Leituras do Passado: historiografia e ensino de história. Rio de Janeiro, Civilização Brasileira, pp.411-436.

THOMPSON, E.P. La Sociedad Inglesa del siglo XVII: Lucha de clases sin clases? In: Tradición, revuelta y consciencia de clase. Barcelona, Editorial Critica, 1984, pp.13-61.

VARIKAS, Eleni. 'O Pessoal é Político': desventuras de uma promessa subversiva. Tempo vol. 2, $\mathrm{n}^{\circ} 3$, Rio de Janeiro, Departamento de História-UFF/Relume Dumará, 1997, pp.59-80.

\section{Matérias de jornais}

O machismo é forte no PCB, diz Zuleika. Jornal República. Rio de Janeiro, 05.11.1979.

Zuleika lança livro e PCB divulga jornal. Diário de Pernambuco. 21.06.1980.

Zuleika Alambert. Partidos desrespeitam a autonomia do movimento feminino. Voz da Unidade. 29.05 a 04.06.1981. 